Revista Perspectivas Online: Exatas \& Engenharias Anais do V Seminário P\&D PROVIC/PIBIC

II Encontro de Iniciação Científica CNPq

Vol. 10, n 29, Suplemento, 2020

\title{
Projeto e confecção de uma cadeira de leito personalizada para idosos
}

\author{
Glauber Soriano Neto ${ }^{1}$, Wiliam Moreira Gomes Neto ${ }^{1}$, Silas das Dores de Alvarenga ${ }^{2}$, Laryce \\ Souza da Silva ${ }^{3}$ \\ (1) Alunos Voluntários de Iniciação Científica do PROVIC/ISECENSA - Curso de Engenharia Mecânica; (2) Pesquisador Colaborador - \\ Laboratório de Análise e Projeto de Sistemas Mecânicos - LAPSIM/ISECENSA;(3) Pesquisadora Orientadora LAPSIM/ISECENSA - Curso de \\ Engenharia Mecânica - Institutos Superiores de Ensino do CENSA - ISECENSA, Rua Salvador Correa, 139, Centro, Campos dos Goytacazes, RJ,

Segundo a organização mundial de saúde (OMS), o idoso é todo indivíduo com 60 anos mais. Essa idade pode variar de acordo com as condições de cada país em relação as Políticas Públicas. Os idosos tendem a apresentar capacidades regenerativas decrescentes, o que pode levar, por exemplo, à fragilidade, um processo de crescente vulnerabilidade, predisposição ao declínio funcional e, no estágio mais avançado, a morte. Além disso, mudanças físicas ou emocionais também podem comprometer a qualidade de vida dessas pessoas. Existem no mercado dispositivos capazes de contribuir para uma melhor mobilidade e independência do idoso. A confecção de uma cadeira de apoio para leito para os idosos agregará positivamente na qualidade de vida desses indivíduos que se encontram acamados. Com o uso desta cadeira, eles serão capazes de sentar-se à beira da cama, evitando complicações provenientes da imobilidade, como pneumonia e úlcera de pressão, já que passam a maior parte do tempo deitados e na mesma posição. O presente trabalho teve como objetivo projetar e construir uma cadeira de apoio para leito adequado para o uso do idoso em situação de imobilidade. O material utilizado na confecção foi policloreto de vinila (PVC), utilizado em instalações hidráulicas. Este possui baixo custo e é resistente mecanicamente para esta finalidade. Em uma visita prévia foram coletados dados como peso e altura dos idosos, e análise do ambiente para dimensionamento e construção da cadeira. Além do levantamento de dados foi realizada uma simulação por elementos finitos utilizando o software Ansys Academic para análise dos esforços sobre a cadeira durante a sua utilização. Por meio do dimensionamento e análise dos esforços, foi possível construir quatro modelos para atender a demanda de um asilo na cidade de Campos dos Goytacazes. Os usuários obtiveram um retorno positivo e imediato da utilização da cadeira e dos benefícios proporcionados por ela.

Palavras-chave: Cadeira de Apoio. Policloreto de Vinila. Simulação.

\section{Instituição de Fomento: ISECENSA}

